\title{
Aprendizaje y práctica de la violencia en la primera socialización
}

\author{
Pilar Lledó ${ }^{1}$
}

La violencia, que impregna todos los niveles de la sociedad en que vivimos, es, sin duda, un fenómeno complejo. No podemos señalar las causas concretas que lo producen, podemos como mucho realizar una aproximación a distintos hechos de tipo social, económico, político, cultural y hasta genético, que inciden de modo determinante en que la violencia se produzca.

Dice Fernando Savater en El valor de educar que la violencia no es un fenómeno perverso, inexplicable y venido de no sé que mundo diabólico, si no un componente de nuestra condición que debe ser compensado y mitigado racionalmente por el uso de nuestros impulsos no menos naturales de cooperación, concordia y convivencia pacífica.

Filósofa española. Exgobernadora civil de Madrid y La Coruña. Universidad Carlos $I 11$ de Madrid. E-mail: airines@ctv.es 
Aquí radica la importancia fundamental de la educación como elemento clave de la prevención de la violencia, y de ahí la conmoción social que genera cualquier tipo de hecho violento, cuando lo realizan niños, adolescentes o jóvenes, durante el período de escolarización.

El Gobierno Francés desde 1994 ha puesto en marcha cuatro planes contra la violencia escolar, en los que se han implicado varios Ministerios. Jospin afirmaba, en la última campaña electoral, que la violencia escolar se había convertido en un verdadero problema político. Y Lang, ministro de educación, constataba que el hecho de reconstruir la autoridad de la escuela y la de quienes trabajaban allí, era uno de los problemas fundamentales de Francia.

Sin embargo, Savater considera que en esta cuestión del papel de la escuela como factor de prevención de la violencia, existe una cierta dosis de hipocresía. A la pregunta ipor qué los jóvenes son violentos? Habría que responder ¿y por qué no habrían de serlo? ¿no lo son sus padres y lo fueron sus abuelos? ¿Es que acaso la violencia no es un componente de las sociedades humanas tan antiguo como la concordia?

De hecho, las agresiones son producto de la intolerancia y del grado creciente de agresividad social. Existe agresividad contra cualquier forma de pobreza: indigentes, inmigrantes, personas de otra raza, cultura o religión. Hay agresividad de unas pandillas de jóvenes contra otros, que no visten, piensan, o tienen sus mismos gustos; de unos conductores contra otros y de todos hacia los peatones; existe agresividad hacia las mujeres, los ancianos, los niños; hay agresividad en los medios de comunicación, especialmente en la T.V., y hasta en los juegos y juguetes de los niños.

Existirá la violencia mientras no acabemos con la vergüenza social del chabolismo y la infra-vivienda, de la miseria y la marginalidad; mientras continúe el fracaso escolar, y 
siga aumentando el número de desempleados; mientras concibamos las ciudades como lugares de explotación y enriquecimiento, en vez de centros de comunicación y diálogo; mientras sigamos tolerando actitudes racistas, xenófobas, o machistas.

Dice Carlos París en su obra Crítica a la civilización nuclear que la fragmentación de nuestra sociedad es la que produce la violencia:

"Hoy nos encontramos con la escisión radical entre parados y trabajadores; el contraste entre aquellos que tienen un trabajo negro, eventual o doméstico, los tributarios de la economía sumergida y los que ganan su salario en las grandes empresas. Con el contraste entre hombres y mujeres respecto a sus derechos laborales, y con la heterogeneidad introducida por los inmigrantes, especialmente de otras razas.

El parado maduro se hunde en la depresión, el joven tira por la calle del medio, e intenta conseguir mediante la violencia, aquello que le niega una sociedad no menos violenta que él. Y ello le aporta al delincuente juvenil la alegría de identificarse con los protagonistas de las aventuras cuyas imágenes llenan las pantallas, contrastando con la monotonía de su vida. Es el placer de sentirse momentáneamente superior, más allá de la raya que los integrados no se atreven a cruzar, de enfrentarse, incluso, con el poderoso Estado, cuando hacen su aparición los representantes del orden público".

Para Savater, los jóvenes no son violentos por razones antisociales, sino por exceso de sociabilidad; tienen tanto afán de normalidad, de parecerse lo más posible al resto del grupo, de conservar su identidad con él, que están dispuestos a exterminar al diferente, a los que pueden amenazar los intereses del propio grupo. 
Esto explicaría las agresiones de grupos juveniles, con claras raíces de racismo o xenofobia.

Sin embargo, a pesar de todas las posibles causas y explicaciones que nos demos acerca de este fenómeno, la violencia juvenil es, en definitiva, un problema de educación en el que todos nos debemos sentir responsables.

Puesto que estos hechos se producen en el seno de una sociedad determinada, es ésta en su conjunto, quien debe sentirse responsable. Se trata de efectuar una labor de prevención para impedir que se produzcan hechos violentos, puesto que, cuando intervienen las fuerzas de seguridad del estado, en su función represiva, es la sociedad en su conjunto la que ha fracasado, los padres, los educadores, los políticos, los medios de comunicación, etc.

La educación en sí misma tiene un componente conservador, porque se trata de educar, no solo de transmitir unos conocimientos, sino un sentido de la vida, un proyecto de ser humano, y un proyecto de sociedad; ahora bien, los que lo estamos transmitiendo lo hacemos con unos condicionamientos determinados, porque vivimos en una sociedad determinada en la que están vigentes unos principios y unos valores determinados, por lo que creo que una de las misiones que se plantean siempre, tanto para la educación de los padres como de la escuela, es la continuidad social.

Kant constata el hecho de que la educación nos viene siempre de otros seres humanos "hay que hacer notar que el hombre sólo es educado por hombres y por hombres que a su vez fueron educados por otros hombres. Si por una vez un ser de naturaleza superior se encargase de nuestra educación se vería por fin lo que se puede hacer del hombre".

Pero si educar, es apoyar de algún modo la continuidad social, deberíamos preguntarnos en qué tipo de sociedad estamos viviendo ahora y por lo tanto qué tipo de valores 
vamos a transmitir, puesto que en esta sociedad en la que vivimos, creo que es cualquier cosa menos tolerante, relajada, armónica, etc.

De las noticias que nos llegan de nuestro entorno, tanto del resto de Europa como de Estados Unidos, se deduce que hay una violencia generalizada; Javier Elzo, sociólogo en el País Vasco, afirma que uno de cada cien jóvenes entre los diez y los doce años ha sufrido algún tipo de agresión sexual en el ámbito escolar, entendiendo por tal no sólo los centros de estudio, sino también el entorno.

Esa violencia según los psicólogos, se aprende en los primeros años de vida durante la primera etapa de socialización, que se realiza a través de los agentes sociales más importantes, la familia, la escuela, los grupos de iguales, los movimientos culturales, los grupos deportivos, etc.

La sociedad de la información en la que estamos ubicados, va a configurar en las nuevas generaciones su concepto del amor, de la solidaridad, del compromiso, de la ética, de la política, de todo aquello que resulta esencial en los seres humanos.

También vivimos en la era de la globalización, pero ¿de qué tipo de globalización estamos hablando? $\mathrm{O}$ aún mejor, ¿qué modo de globalización defendemos?.

Savater dice que vivimos en un mundo globalizado, pero queda mucho por globalizar, así, se globaliza el comercio, la geoestrategia, la economía, las finanzas, las telecomunicaciones, pero no se afronta globalmente la guerra, el hambre, el medio ambiente, las libertades públicas, la discriminación racial o sexual, etc.

El movimiento antiglobalización, con todos sus fallos, intenta afrontar este problema, y comprometerse, y obligar a los Gobiernos a que se comprometan en un proceso distinto de globalización. 
También para este hecho debemos educar a los niños y a los jóvenes. Porque, de lo contrario, la violencia resulta inevitable.

No se pueden confundir conceptos como información, instrucción y educación. Balmes decía que "educar consiste en formar fábricas y no en construir almacenes", no se trata de acumular información, sino de ser capaces de saber qué hacemos con ella.

La familia es la principal fuente de socialización, porque transmite a los más jóvenes las pautas de comportamiento y los valores de una sociedad determinada, allí se efectúa por vía emotiva y no racional, pero, al igual que la escuela, tampoco es neutra, está adaptada a las exigencias del medio ambiente en el que se desarrolla, a su situación económica, cultural, social, etc., y transmite a los hilos sus propios sentimientos y valores dependiendo de su comprensión del mundo.

Creo que los padres somos los primeros que con nuestras actitudes fomentamos la insolidaridad, los prejuicios sociales, la competitividad, etc., de manera que llegamos a convencer a nuestros hijos, de algo que la sociedad nos dice continuamente, o eres un triunfador, al precio que sea, o eres un fracasado, no hay término medio. $Y$ los fracasados no tienen sitio en esta sociedad.

También se dice que como la familia está en crisis, tampoco puede cumplir ese papel socializador. Creo que una de las causas de estos problemas está en la crisis de autoridad que hay en la sociedad, y que también se contagia a la familia. Queremos que como nosotros no controlamos a nuestros hijos los controlen los maestros, la policía, los jueces etc., cualquiera menos nosotros mismos.

La palabra autoridad etimológicamente no significa mandar, sino hacer crecer; el niño necesita que le pongan limites desde los primeros años, porque si crece sin sentido 
de la autoridad, no por ello va a ser más libre, sino que la pérdida de la autoridad lo conduce a la inseguridad, porque el niño no sabe a qué atenerse, y al miedo que desemboca fácilmente en actitudes delictivas.

Savater afirma que otro de los temas por los que la familia está en crisis es por que existe "la moda" de lo juvenil, los padres no quieren ser padres, sino amigos de sus hijos, a los profesores les sucede lo mismo y un padre no es un amigo, es un padre, y un profesor no es un amigo, es un profesor; los amigos constituyen un factor de socialización distinto, la socialización entre iguales.

Este auge de lo juvenil, se da como consecuencia del rechazo de la experiencia, del rechazo de la ancianidad y en definitiva del miedo a la muerte.

Si este papel de socialización no lo cumple la familia recurrimos a la escuela, por lo que los maestros además de instruir tenemos que formar la conciencia social y moral del niño, tenemos que incrementar en ellos el principio de realidad para que acepten el esfuerzo del aprendizaje en una sociedad en la que todo les ha sido dado con sentarse en un sillón y dar a una tecla.

Freihet decía "Nunca darás de beber al caballo que no tenga sed, porque si le metes la cabeza en el agua; lo único que lograrás es que se ahogue".

Este es uno de los grande retos a los que hoy nos enfrentamos los educadores: ser capaces de despertar la sed de saber, la ilusión de saber, el compromiso de saber.

Y hacerlo en un medio hostil, en el que las imágenes invaden nuestra intimidad y nuestro entendimiento, impidiéndonos reflexionar.

Dice Savater también que la televisión no es que no eduque, sino que educa demasiado, y con una fuerza irresistible, nos enseña las verdades de la carne: el sexo, la enfermedad y la muerte, y nos enseña las verdades de la fuerza: el 
éxito de la violencia y de la guerra; continuamente reproduce modelos de vida, ejemplos y contra ejemplos. Juan Carlos Tudesco añade: la televisión reproduce la mecánica de socialización primaria empleada por la familia o en la escuela, pues socializa a través de gestos, de climas afectivos, de tonalidades de voz, y promueve por ello emociones, creencias y adhesiones totales.

Si la familia no puede ser neutral, la escuela tampoco puede serlo, lo que no quiere decir que sea partidista, pero sí tiene que ser política, tiene que conducir a un proceso de socialización determinado, de cara a una democratización humanista, que es tanto como decir universal.

Puesto que la educación tiene una dimensión conservadora, hace que muchas veces los padres vivan la escuela como un tranquilizante, que les quita una gran responsabilidad de encima, y además les transmite confianza. Pero la escuela no sólo transmite la cultura dominante, sino que transmite el conjunto de culturas que hay en conflicto en un momento determinado y en un espacio determinado.

Ana Arendt, en la Crisis de la Educación dice: "quienes pretenden educar, se hacen responsables del mundo, que no es aprobarlo tal y como es, sino asimilarlo conscientemente porque solo a partir de ahi se puede cambiar".

Muchas veces no existe sintonía entre lo que se imparte en la escuela y la realidad que vive el muchacho en su casa y su barrio. Si nadie refuerza su escolaridad de alguna manera, se producirá el fracaso escolar necesaria mente.

Porque sí la información que reciben, no les resulta de ninguna utilidad para desenvolverse en el mundo que les rodea, si les resulta tan extraña que apenas pueden comprenderla, la respuesta de los muchachos será la huida. La huida de una fuente de frustraciones que les arrebata la energía que ellos necesitan para sobrevivir en su medio generalmente hostil. 
Si se sienten en la escuela como el malo de la película, los que ya saben que son malos, y como el tonto del barrio los que ya saben que son tontos, en referencia con los que socialmente se les considera como listos, todo ello deteriora gravemente la autoestima de los muchachos y genera agresividad, que de alguna manera tienen que resolver.

Sigue diciendo Savater en El valor de educar: "La escuela no basta con que enseñe a los alumnos unos cuantos conocimientos y habilidades para desempeñar un oficio, ni mucho menos con inculcarles hábitos de obediencia y respeto, ni siquiera de inconformismo. No, es necesario algo más: hay que entregarles la completa perplejidad del mundo, nuestra propia perplejidad, la dimensión contradictoria de nuestras frustraciones y nuestras esperanzas. Que les trasmitimos lo que creemos mejor de lo que fuimos pero que sabemos que les será insuficiente, como fue insuficiente también para nosotros. Que lo transformes todo, empezando por sí mismos, pero conociendo qué es y cómo es lo que quieren transformar. El sentido de la escuela es conservar y transmitir el amor intelectual a lo humano".

El otro pilar en el que se apoya la primera socialización, es el entorno del niño. Nadie nace con los genes del vicio, del crimen, de la violencia, de la marginación social, etc. El niño está dotado de una serie de tendencias constructivo-destructivas y dependiendo del medio ambiente en el que se desarrolla, éstas evolucionarán hacia una situación u otra, cosa que en los primeros momentos de la socialización, resulta imprevisible.

Creo que la herencia mayor que nos dejan nuestros padres más que la genética, es el medio en el que nos estamos desarrollando, esa es la mayor herencia, empezando por los propios padres. Que los padres estén presentes o ausentes, que sean unos padres normales o demasiado protectores, que quieran a los niños o no los quieran, que sean 
tolerantes o intolerantes, que sean cultos o incultos, que estén integrados en la sociedad, o sean unos seres marginales, etc., de todo ello depende muchísimo el futuro del muchacho.

La entrada del niño en el grupo de iguales es muy importante, pero su orientación depende de dos factores; en primer lugar depende de las condiciones, especialmente emocionales, en que el niño se haya desarrollado en el seno de la familia y en la propia escuela; en segundo lugar depende de las características del grupo, en el que el chaval se inserte, y de los objetivos fundamentales de la nueva pandilla.

Si en esta primera etapa de socialización, el muchacho no ha tenido una situación emotiva ni emocional resuelta con sus padres ni en la escuela, si de verdad su autoestima está por los suelos, si se le ha hecho sentir inseguro y con miedo, entonces el grupo, la pandilla, los colegas, o le van a reafirmar en esa inseguridad, o le van a dar la seguridad que necesita, la autoafirmación y desgraciadamente la autoridad que no le han dado los padres y los profesores.

Pero como decíamos anteriormente de la escuela y de los padres, estas pandillas no son neutras. Viven y se desarrollan en un ambiente en el que lo que cuenta es ser el mejor, el más fuerte, el que detenta el mayor poder.

$Y$ ese poder no ven que puedan conseguirlo ni con una mayor instrucción, ni asumiendo unos valores tales como la tolerancia, la solidaridad, o el compromiso, sino más bien, mediante la imposición por la fuerza, y si fuera necesario mediante la violencia.

Estos grupos, la mayoría de las veces, le proporcionan al adolescente o al joven la sensación de pertenencia a un grupo, y con ello el sentimiento de su propia identidad y de su autoestima, al sentirse reconocido y aceptado, incluso querido, sentimientos que no habrán sido capaces de despertar ni los padres, ni la escuela. 
De ahí la importancia de la orientación de estos grupos, porque de ella depende el futuro de estos jóvenes como seres sociales, o como personas marginales, tendentes a la delincuencia.

Existen una serie de posibles medidas para prevenir la violencia en este primer período de socialización. Pueden parecer utópicas, y según los lugares donde se pretendan aplicar, casi imposibles; sin embargo, creo que conviene tenerlas en cuenta.

Por ejemplo, la creación de observatorios de la violencia en los ámbitos escolares, que puedan prevenir y en su caso gestionar las situaciones de riesgo escolar.

Medidas dirigidas a la familia como crear escuelas de padres allá donde no las haya y potenciar las que existen, $\mathrm{o}$ crear unidades de asistencia para los padres cuyos hijos están en situación de riesgo.

Medidas para el centro educativo como fomentar y potenciar la formación de los niños en materias transversales, tales como educación para la paz, educación para la convivencia, lo cual significa un aumento del profesorado en estos temas, igual que una formación del profesorado para poder abordarlos; potenciar los equipos psicopedagógicos y de orientación escolar; potenciar las iniciativas educativas alternativas destinadas a la reinserción en el sistema educativo de los jóvenes que lo han abandonado; potenciar las comisiones de convivencia; incrementar el control del absentismo escolar; impulsar la formación de los propios educadores; crear aulas de derecho en los centros, y medidas en el entorno escolar como impulsar la figura de los educadores de barrio, así como que los centros escolares, estén abiertos fuera del horario escolar, para atender las necesidades del barrio, especialmente la biblioteca, los centros deportivos, salón de actos etc. para que verdaderamente haya interacción barrio-escuela. 
Pero, más allá de estas medidas concretas sería muy positivo que a los niños, en este primer período de socialización se les enseñara a ser felices.

Dice el proverbio chino "Soy bueno porque soy feliz, no soy feliz porque soy bueno". 